\title{
On the Ratio between Static Pressure and Thickness of Growing AAAs
}

\author{
Daniele Bruschetta ${ }^{1}$, Debora Di Mauro ${ }^{1}$, Vincenzo Filardi ${ }^{2 *}$, Giuseppina Rizzo ${ }^{1}$, Fabio Trimarchi $^{1}$
}

${ }^{1}$ Dipartimento di Scienze Biomediche e delle Immagini Morfologiche e Funzionali, University of Messina, Via Cons. Valeria, 1 C/O A. O.U. Policlinico "G. Martino" - 98125 MESSINA

${ }^{2}$ C.A.R.E.C.I., University of Messina, Via Consolato del mare, 4198121 Messina, Italy

\begin{abstract}
Objective: Abdominal aortic aneurysms (AAAs) are characterized by structural remodelling resulting in the gradual weakening and expansion of the aortic wall. Wall stress may furnish a usable indicator to prevent the failure. In order to evaluate this risk, static pressure aging on the cap was used to perform FEA, simulating an aneurysm varying its dimensions from $10 \mathrm{~mm}$ to $50 \mathrm{~mm}$. Analyses were carried out by imposing different thickness of the cap, and obtaining correspondent equivalent Von Mises stresses. Understanding how these stresses are distributed and what factors influence stress distributions is critical in evaluating the potential for rupture.
\end{abstract}

Methods: A representative FE model was created in order to simulate the historical evolution of the AAA. CFD analyses were performed to obtain data of the static pressure aging on the model. Patient informed consent and IRB approval were obtained. A linear law was speculated to understand thickness thinning in function of aneurysm's growth. The obtained pressure maps were used as input to perform elastic linear analyses on the five different FE wrappings.

Results: If the bloody pressure is increased, that increases also wall shear stress, and an adaptive increase in arterial luminal size is observed. Results have evidenced peaks of stress varying from 0,004 MPa, for a diameter of $10 \mathrm{~mm}$, to $0,45 \mathrm{MPa}$, for a diameter of $50 \mathrm{~mm}$. Top and bottom zones of aneurysm result more solicited than the middle ones, as it can be deducted by obtained strain values, ranging from $5,84 \mathrm{e}-7$, for a diameter of $10 \mathrm{~mm}$, to $3,14 \mathrm{e}-4$, for a diameter of $50 \mathrm{~mm}$. In order to evaluate the mechanical behaviour of the cap, related to its thickness at $50 \mathrm{~mm}$ of diameter, different FEA were conducted varying thickness, uniformly, from 1 to $0.4 \mathrm{~mm}$. As it is possible to notice, stress increases exponentially while thickness decreases.

Conclusions: Results indicate an equivalent Von Mises stress of about $0,45 \mathrm{MPa}$, close the to failure value, for a critical dimension of $50 \mathrm{~mm}$. This means that failure conditions can depend at least, by two variables: thickness and pressure.

Keywords: Abdominal aortic aneurysm; CAD; FEA

Abbreviations: FE: Finite Element; FEA: Finite Element Analysis; CFD: Computational Fluid Dynamics; FSI: Fluid Structure Interaction; ILT: Intraluminal thrombus

\section{Introduction}

Abdominal aortic aneurysms (AAA) are characterized by structural remodelling resulting in the gradual weakening and expansion of the aortic wall. Surgical interventions in repairing AAA have significantly developed in recent years 3-6\%, reducing causes of death in patients of over 65 years of age, any case when rupture occurs $50 \%$ of patients die before reaching hospital [1].

AAA can typically remain stable until the strength of the aortic wall is unable to withstand the forces acting on it as a result of the luminal blood pressure, resulting in AAA rupture. This condition is growing in prevalence in the elderly population, with approximately 150,000 new cases being diagnosed every year $[1,2]$. An AAA may rupture if it is not treated, and this is ranked as the 13th most common cause of death in the US [3]. The prevalence of abdominal aortic aneurysms (AAA) in the general population is 4-10\%, [4-6]. The clinical treatment of AAA patients presents a dilemma for the surgeon: surgery should only be recommended when the risk of rupture of the AAA outweighs the risks associated with the interventional procedure. The surgical decision is based on the AAA diameter, its expansion rate, the patient's age and risk, the individual centre's surgical morbidity and mortality and the local experience of endovascular repair. Predicting the expansion of small AAA and modifying possible risk factors are important for clinical management. Decision making in regard to elective AAA repair therefore requires careful assessment of rupture risk, operative mortality and life expectancy [7]. Current approach suggests intervening when AAA reaches critical dimensions estimated in a diameter of $5.5 \mathrm{~cm}$. This isn't a values which has scientific bases as the aneurysm can also expand without rupture, or from the other hand other aneurysms (10-24\%) can fail also if smaller [8,9]. Current AAA repair procedures are expensive and carry significant morbidity and mortality risks [8]. Depending on the health conditions, the age, and compliances the decision to operate a patient is not always an easy solution. Many complications can arise after operation [10] and any case the decision to operate or not has always many risks.

The maximum diameter criterion seems to be the largest used method, as a critical dimension of $5.5 \mathrm{~cm}$ is reached by the aneurysm, should be convenient to operate [11], but not scientific basis $[8,12]$ can effort the criterion. Literature shows different cases of ruptures occurred in small aneurysms $[13,14]$, and singular cases of giant aneurysms with an unexpected life span [8]. Studies have demonstrated micro structural changes characterized by an unbalancing of the elastin/collagen equilibrium and altered production of the extra cellular matrix, [15].

*Corresponding author: Filardi Vincenzo, C.A.R.E.C.I., University of Messina Via Consolato del mare, 4198121 Messina, Italy, Tel: 390906768264; E-mail: vfilardi@unime.it

Received January 13, 2015; Accepted February 06, 2015; Published February 08, 2015

Citation: Bruschetta D, Mauro DD, Filardi V, Rizzo G, Trimarchi F (2015) On the Ratio between Static Pressure and Thickness of Growing AAAs. J Vasc Med Surg 3: 185. doi:10.4172/2329-6925.1000185

Copyright: ( 92015 Daniele B, et al. This is an open-access article distributed under the terms of the Creative Commons Attribution License, which permits unrestricted use, distribution, and reproduction in any medium, provided the original author and source are credited. 
However, the initiating event or events of aneurysm formation and/ or rupture have not been clearly delineated. However, the problem with this approach is that $1 \%$ to $4.5 \%$ of AAAs rupture with an AP diameter of $5.5 \mathrm{~cm}[16,13]$. Just as important is what happens to the AAA wall following exclusion therapy. In particular, there has been an accelerated use of endovascular techniques in recent years, yet a small ongoing risk of AAA rupture remains $[17,18]$. We should be able to predict this event by more reliable means than simply looking for continued pressurization of the sac. Attempts have been made to develop more refined markers of rupture, which might be applied in scenarios of endoleak following endovascular repair, which can anticipate a further intervention. The pressure inside the AAA sac is however to be monitored as strictly connected with the risk of rupture.

Also proximal neck dilatation can be identified as a possible cause of risk as contributes to the aortic weakening [19]. So many causes can play an important rule in aneurysms generation and degeneration or stabilization as reported in literature [20] and a not scientific proved criterion can give guaranties about the necessity to operate or not [21].

As it is obvious a rupture in AAA occurs when the induced stress overcome the critical stress of the material. The process evolves by a progressive impairment of the wall tissue which is forced to enlarge by the bloody pressure. As the wall tissue enlarges is thickness decreases reducing its capability to resist at the induced pressure. As theory demonstrates for spherical vessels subject to internal pressure, the maximum stress is reached at maximum diameters, calculated by taking into account the direction of the flowing current, and is inversely proportional to the thickness.

The phenomenon of the rupture in AAA is still not totally clear as two contradictory aspects play an important rule. The first one concerns that a not definable critical dimension can be individuated to establish a threshold value, second one concerns the problem that sometime they fail also if they are significantly under critical dimensions. The problem consists in evaluating the relationship between local thickness and local stress aging on the wall only this can furnish indications about rupture. Different studies have investigated about mechanical properties of aneurysms $[7,22,15]$.

However, there have been only two studies that reported on mechanical properties of ruptured AAA presumably because they rarely become available for studies $[23,24]$. This limits our ability to reliably assess differences between these lesions. Earlier studies have reported on wall thickness and failure strength by testing specimens taken from the anterior midsection of an AAA [15]. However, they did not provide information on regional variation in these characteristics. For example, Sekhar and Heros [25], discuss competing hypotheses on the pathogenesis and Humphrey [26], reviews biomechanical factors that have been implicated in lesion development. Of particular note here, it has been hypothesized that saccular aneurysms enlarge and rupture (a) due to limit point instabilities [27,28], (b) when the equilibrium wall stress exceeds the strength of the wall $[29,30]$, or (c) because the dynamic behaviour of the wall is unstable in response to pulsatile blood flow [31]. Starting from the consideration that stresses increase as diameter increases and thickness decreases, it is logical to relate risk of rupture to aneurysm size. However, because AAA have complicated asymmetric shapes, the relationship is more complex, and the stress in an AAA will depend on the entire geometry, as confirmed by recent improvements in the knowledge of AAA geometry, coupled with the advances in imaging technique. For this reason this paper aims to analyse by a FE code the wall stress shielding aging on the cap of aneurysm starting from static pressure data obtained previously [32], for an aneurysm starting from $10 \mathrm{~mm}$, and growing to $50 \mathrm{~mm}$. Stress and strain aging on the cap were identified and different thicknesses were considered as well.

\section{Material and Methods}

Three male patients, aged 65,66 , and 70 , affected by AAA (diameters of $35 \mathrm{~mm}, 58 \mathrm{~mm}$, and $51 \mathrm{~mm}$ ), were selected for this study. The required information was focused on the geometry of the AAA lumen, material property of the wall, and flow conditions at the model boundaries. All patients were given contrast agent and scanned with a spiral CT scanner (Mx 8000 IDT, Philips), for their routine AAA examinations. Parameters of CT acquisitions are decided by operator and surgeon. In order to reconstruct AAA geometry the CT slices were segmented by region growing method (RGM) to evidence to lumen boundaries. At the end a process of smoothing and reconnecting of segments was carried on to obtain a correct geometry.

Medium thickness were calculated respectively for AAA of $35 \mathrm{~mm}$ resulting in $1.81 \mathrm{~mm}$, for AAA of $58 \mathrm{~mm}$ resulting in $0.55 \mathrm{~mm}$, and the last one, $51 \mathrm{~mm}$, resulting in $0.6 \mathrm{~mm}$. Raghavan et al. [32] carried on a study on three unruptured and one ruptured AAA founding a lower thickness of $0.23 \mathrm{~mm}$ on the ruptured one, close to the failure zone. Differently they found a maximum thickness of $4.26 \mathrm{~mm}$ in the smaller of the three $(\mathrm{D}=40 \mathrm{~mm})$. A representative FE model was created in order to simulate the historical evolution of the AAA, using information previously described. Moreover by analysing all the data, a linear law was speculated in order to understand minimum thickness thinning in function of aneurysm's growth (Table 1 and Figure 1). In Table 1 are reported, for each growing step of aneurysm from 5 $\mathrm{mm}$ to $50 \mathrm{~mm}$ of diameter, the supposed minimum cap thickness, and consequently internal and external diameters and volumes, and also the difference between them. In Figure 1, the continuum lines represent trend curves while quads the obtained data, as it is possible to notice the difference in volumes is a third grade curve with a the peak at $40 \mathrm{~mm}$ of diameter. The obtained results were used to perform CFD and FE analyses. Finally five FE models were developed with "Hypermesh", a FE code by Altair", simulating five growing steps from 10 to $50 \mathrm{~mm}$ of diameter for AAA (Figure 2). After the pressure fields were obtained, the five different $\mathrm{FE}$ wrappings were used as input to carry on the elastic linear analyses by using MSC MARC code. Caps were assumed to be isotropic, with a density of $2000 \mathrm{~kg} / \mathrm{m}^{3}(2.0 \mathrm{~g} /$ $\mathrm{cm}^{3}$ ), Young's modulus of $\mathrm{E}=2.7 \mathrm{MPa}$, Poisson ratio of $v=0.45$, and undergo large displacements. The wall model was recently used in FSI and solid studies $[33,34]$ evidencing a not significant dependence of the wall stress values by material properties of the wall.

\begin{tabular}{|c|c|c|c|c|c|}
\hline $\begin{array}{c}\text { Cap } \\
\text { tickness } \\
{[\mathrm{mm}]}\end{array}$ & $\begin{array}{c}\mathbf{D}_{\text {ext. }} \\
{[\mathrm{mm}]}\end{array}$ & $\begin{array}{c}\mathbf{V}_{\text {ext. }} \\
{\left[\mathrm{mm}^{3}\right]}\end{array}$ & $\begin{array}{c}\mathbf{D}_{\text {int. }} \\
{[\mathrm{mm}]}\end{array}$ & $\begin{array}{c}\mathbf{V}_{\text {int. }} \\
{\left[\mathrm{mm}^{3}\right]}\end{array}$ & $\begin{array}{c}\Delta \mathbf{V}=\mathbf{( V}_{\text {ext. }} \\
\mathbf{V}_{\text {int }} \text { ) } \\
{\left[\mathrm{mm}^{3}\right]}\end{array}$ \\
\hline 0,50 & 50 & 65417 & 49,49 & 63439 & 1978 \\
\hline 0,83 & 45 & 47689 & 44,16 & 45074 & 2615 \\
\hline 1,10 & 40 & 33493 & 38,90 & 30805 & 2688 \\
\hline 1,40 & 35 & 22438 & 33,59 & 19841 & 2597 \\
\hline 1,73 & 30 & 14130 & 28,26 & 11817 & 2313 \\
\hline 2,01 & 25 & 8177 & 22,98 & 6356 & 1821 \\
\hline 2,32 & 20 & 4187 & 17,67 & 2890 & 1296 \\
\hline 2,62 & 15 & 1766 & 12,37 & 993 & 774 \\
\hline 2,94 & 10 & 523 & 7,06 & 184 & 339 \\
\hline 3,30 & 5 & 65 & 1,70 & 3 & 63 \\
\hline
\end{tabular}

Table 1: Numerical values of minimum cap thickness, internal and external diameters and volumes, and volume differences. 

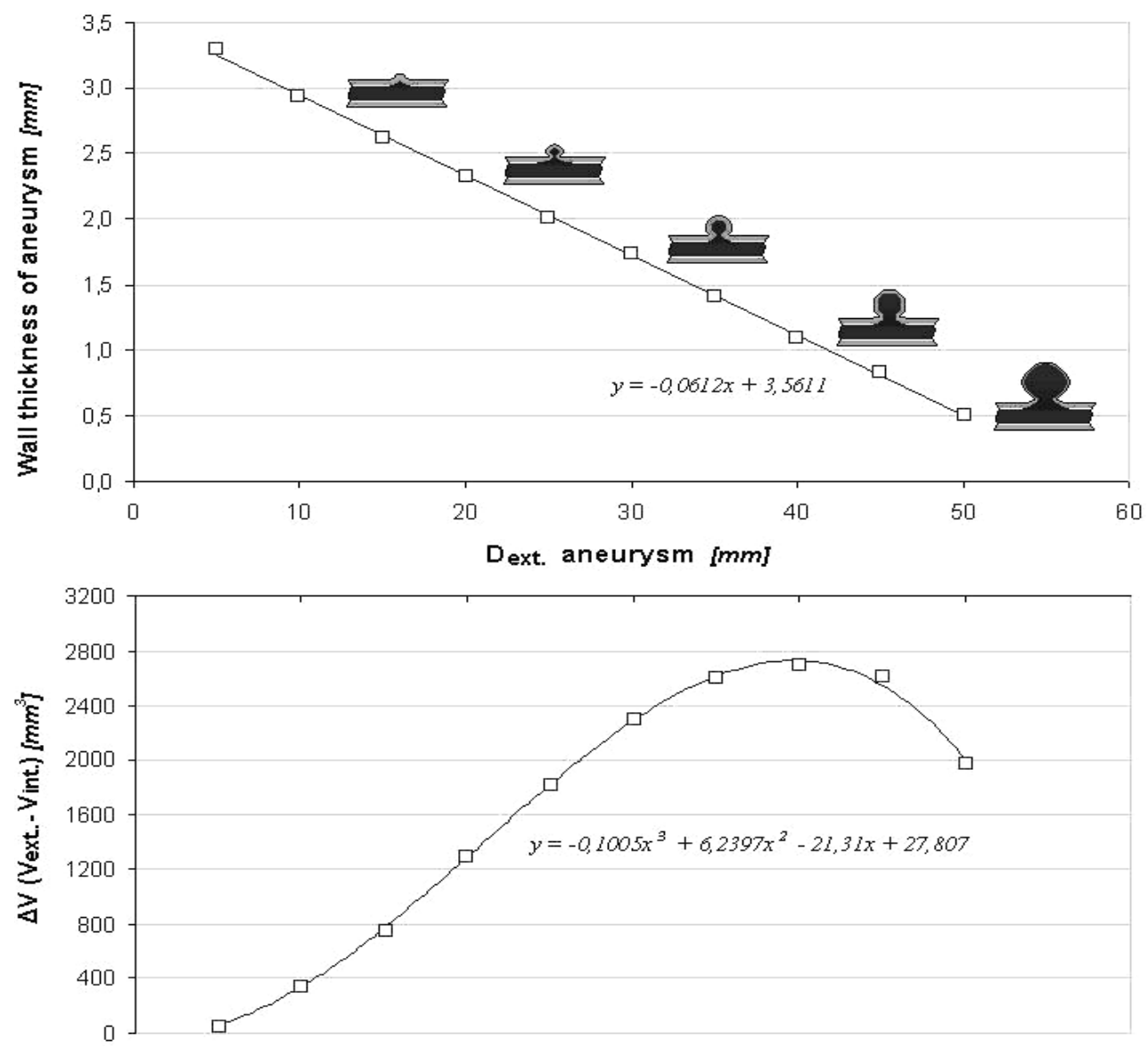

Figure 1: Minimum Wall thickness and volume difference vs. growing diameters.

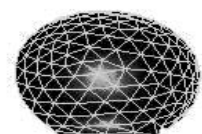

$D=40[\mathrm{~mm}] \quad t=1,10[\mathrm{~mm}]$

Figure 2: FE models of the growing aneurysm. 
Citation: Bruschetta D, Mauro DD, Filardi V, Rizzo G, Trimarchi F (2015) On the Ratio between Static Pressure and Thickness of Growing AAAs. J Vasc Med Surg 3: 185. doi:10.4172/2329-6925.1000185

Page 4 of 8

\section{Results}

The results of the examinations conducted in a precedent research [32], were reported in Table 2, which reports data, at the peak systole along the axial direction, and inside the cap, of static pressure of the aneurysm at the different growing steps, from 10 to $50 \mathrm{~mm}$ of diameter. Peaks of pressure increase, related to the aneurysm's growing, from about 17 to $19 \mathrm{MPa}$. With regard to fluid dynamics, especially on the entrance of aneurysm's regions, the areas of low wall shear stress are also associated with flow separation, that is, a reversal or disturbance of the flow, and a greater fluctuation of wall shear stress. This may be important because it has been suggested that the fluctuation of the wall shear stress or disturbed flow leads to increased endothelial cell turnover and intimal thickening. If the blood flow is increased, that increase wall shear stress, an adaptive increase in arterial luminal size is observed. If the blood flow is decreased, usually insight the aneurysm, there is an adaptive decrease of thickness in the cap. In Table 3 are reported results obtained by stress strain analyses carried on by the FE code. The Y coordinate values of nodes were reported following the semi circular contour shape for each growing step, thus that the whole profile of aneurysms, in terms of stress and strain, can be exploited on the X Y plane. In the remaining columns Von Mises equivalent stress and strain were reported as well. As it is possible to notice by Table 3 and Figure 3, Von Mises stresses growth with increasing of dimensions and consequently reducing the intimal thickening of aneurysm's cap. Peaks of stress vary from $0,004 \mathrm{MPa}$, on the top of $10 \mathrm{~mm}$ aneurysm, to 0.45 , on the base of $50 \mathrm{~mm}$ aneurysm. Consequently top and bottom zones of aneurysm result more solicited than the middle ones, as it can be deducted by observing strain values of table. Peaks of strains vary from $5.84 \mathrm{e}-7$, on the top of $10 \mathrm{~mm}$ aneurysm, to $3.14 \mathrm{e}-4$, on the base of $50 \mathrm{~mm}$ aneurysm. Finally in Figure 4 are reported the curves of the $\mathrm{Y}$ coordinate values in function of the corresponding Von Mises stresses, and in Figure 5 the corresponding strains.

In order to evaluate the mechanical behaviour of the cap, related to its thickness at $50 \mathrm{~mm}$ of diameter, different FEA were conducted varying thickness, uniformly, from 0,7 to $0.3 \mathrm{~mm}$. Results in terms of equivalent Von Mises stress and strain were reported in Table 4 and Figure 6. As it is possible to notice increment in stress reflects a reduction in thickness.

\begin{tabular}{|c|c|c|}
\hline $\begin{array}{c}\text { D } \\
{[\mathrm{mm}]}\end{array}$ & $\begin{array}{c}\text { Max. Static press. aging } \\
\text { on the whole artery } \\
{[\mathrm{Pa}]}\end{array}$ & $\begin{array}{c}\text { Max. Static press. aging on the } \\
\text { aneurysm's cap } \\
{[\mathrm{Pa}]}\end{array}$ \\
\hline 10 & 16801 & 16801 \\
\hline 20 & 16364 & 16080 \\
\hline 30 & 17069 & 17069 \\
\hline 40 & 18012 & 18012 \\
\hline 50 & 19305 & 19290 \\
\hline
\end{tabular}

Table 2: Maximum values of static pressure aging on the whole artery and on the cap at the different growing steps of the aneurysm.

\section{Discussion}

The formation of an aneurysm within the abdominal aorta presents a dilemma requiring clinicians to predict when the risk of rupture outweighs that associated with intervention. The most commonly used criterion for AAA rupture prediction is the maximum diameter criterion, which is typically based on a cut-off value of $5.5 \mathrm{~cm}$ [35]. Other parameters that have been proposed as potential predictors of AAA rupture include the AAA expansion rate [36,37] wall stiffness, [38] increase in ILT thickness, volume of ILT, wall tension [39], and peak AAA wall stress [40]. All of these approaches are empirical in nature and, as such, fail to take into account the physical aspects that control AAA development and rupture. The degeneration and the regeneration of aneurismal tissue during its natural history are likely manifested in the mechanical properties and structural content. The cause(s) and prognostic indicator(s) of AAA rupture continue to elude our understanding largely because studies on lesions that did rupture are scarce. This may mainly be attributed to the unavailability of ruptured AAA specimens for studies. While there have been many studies on AAA mechanical properties [22,24,41-44], the source of specimens for such studies have mainly been the AAA tissue that becomes available during the open surgical resection of unruptured lesions. The behaviour of AAA strongly depends on the AAA diameter [45-47]. AAA smaller than $3.5 \mathrm{~cm}$ are stable, less than $10 \%$ reached 5 $\mathrm{cm}$ during the whole follow-up period. AAAs ranging from 3 to 3.9 $\mathrm{cm}$ expand slowly, with a mean growth rate of $2.07 \mathrm{~mm} / \mathrm{year}$, and rarely have ruptured throughout the follow-up. Over $25 \%$ of them did not expand at all, over a mean follow-up of 3.5 years. The UK SAT estimated for the same class of AAA size a rupture risk to of $0.9 \%$ for 100 person-years [45]. These are often young patients with high long-

\begin{tabular}{|c|c|c|c|c|c|c|c|c|c|c|c|c|c|c|}
\hline \multicolumn{3}{|c|}{$\begin{array}{c}D=10 \mathrm{~mm} \\
t=2,94 \mathrm{~mm}\end{array}$} & \multicolumn{3}{|c|}{$\begin{array}{c}D=20 \mathrm{~mm} \\
t=2,32 \mathrm{~mm}\end{array}$} & \multicolumn{3}{|c|}{$\begin{array}{c}D=30 \mathrm{~mm} \\
t=1,73 \mathrm{~mm}\end{array}$} & \multicolumn{3}{|c|}{$\begin{array}{l}D=40 \mathrm{~mm} \\
t=1,10 \mathrm{~mm}\end{array}$} & \multicolumn{3}{|c|}{$\begin{array}{l}D=50 \mathrm{~mm} \\
t=0,5 \mathrm{~mm}\end{array}$} \\
\hline $\begin{array}{c}\mathbf{Y} \\
{[\mathrm{mm}]}\end{array}$ & $\begin{array}{c}\text { V.M. } \\
\text { Stress } \\
{[\mathrm{MPa}]}\end{array}$ & $\underset{\%}{\text { Strain }}$ & $\begin{array}{c}\mathbf{Y} \\
{[\mathrm{mm}]}\end{array}$ & $\begin{array}{c}\text { V.M. } \\
\text { Stress } \\
\text { [MPa] }\end{array}$ & $\underset{\%}{\text { Strain }}$ & $\begin{array}{c}\mathbf{Y} \\
{[\mathrm{mm}]}\end{array}$ & $\begin{array}{c}\text { V.M. } \\
\text { Stress } \\
{[\mathrm{MPa}]}\end{array}$ & $\underset{\%}{\text { Strain }}$ & $\begin{array}{c}\mathbf{Y} \\
{[\mathrm{mm}]}\end{array}$ & $\begin{array}{l}\text { V.M. } \\
\text { Stress } \\
\text { [MPa] }\end{array}$ & $\underset{\%}{\text { Strain }}$ & $\begin{array}{c}\mathbf{Y} \\
{[\mathrm{mm}]}\end{array}$ & $\begin{array}{l}\text { V.M. } \\
\text { Stress } \\
\text { [MPa] }\end{array}$ & $\underset{\%}{\text { Strain }}$ \\
\hline 10,00 & 0,004 & $5,84 \mathrm{e}-7$ & 20,00 & 0,018 & $6,63 e-6$ & 30,00 & 0,074 & $4,46 e-5$ & 40,00 & 0,118 & $7,11 \mathrm{e}-5$ & 50,00 & 0,459 & $3,14 \mathrm{e}-4$ \\
\hline 9,47 & 0,004 & $5,41 \mathrm{e}-7$ & 19,03 & 0,012 & $4,53 e-6$ & 29,01 & 0,040 & $3,13 e-5$ & 39,43 & 0,073 & $3,77 e-5$ & 49,29 & 0,218 & $9,63 e-5$ \\
\hline 8,06 & 0,002 & $5,24 \mathrm{e}-7$ & 16,66 & 0,007 & $3,35 e-6$ & 27,43 & 0,020 & $2,27 e-5$ & 37,66 & 0,033 & $2,72 e-5$ & 47,45 & 0,109 & $8,69 e-5$ \\
\hline 6,33 & 0,001 & $4,92 \mathrm{e}-7$ & 13,63 & 0,004 & $3,02 \mathrm{e}-6$ & 24,51 & 0,015 & $1,41 \mathrm{e}-5$ & 35,14 & 0,022 & $2,47 e-5$ & 44,79 & 0,060 & $8,53 e-5$ \\
\hline 5,30 & 0,001 & $2,07 e-7$ & 11,69 & 0,004 & $2,05 e-6$ & 20,61 & 0,016 & $1,38 e-5$ & 31,66 & 0,021 & $2,30 e-5$ & 41,56 & 0,050 & $7,54 \mathrm{e}-5$ \\
\hline 3,93 & 0,002 & $3,93 e-7$ & 9,54 & 0,006 & $1,18 \mathrm{e}-6$ & 16,29 & 0,015 & $1,38 e-5$ & 27,77 & 0,021 & $2,21 \mathrm{e}-5$ & 37,69 & 0,051 & $6,89 e-5$ \\
\hline \multirow[t]{8}{*}{1,43} & 0,002 & $1,23 e-7$ & 7,06 & 0,009 & $1,76 \mathrm{e}-6$ & 11,70 & 0,013 & $1,32 \mathrm{e}-5$ & 23,20 & 0,021 & $2,21 \mathrm{e}-5$ & 33,32 & 0,052 & $6,75 e-5$ \\
\hline & & & 2,86 & 0,008 & $1,81 \mathrm{e}-6$ & 7,80 & 0,024 & $2,03 e-5$ & 18,80 & 0,024 & $2,00 e-5$ & 28,51 & 0,058 & $6,73 e-5$ \\
\hline & & & & & & 4,29 & 0,025 & $1,03 e-5$ & 14,57 & 0,041 & $1,86 e-5$ & 23,76 & 0,070 & $6,04 e-5$ \\
\hline & & & & & & & & & 10,29 & 0,071 & $1,52 \mathrm{e}-5$ & 18,81 & 0,090 & $5,65 e-5$ \\
\hline & & & & & & & & & 6,80 & 0,122 & $3,48 e-5$ & 14,57 & 0,119 & $5,08 e-5$ \\
\hline & & & & & & & & & 5,71 & 0,159 & $1,53 e-5$ & 10,71 & 0,161 & $3,34 \mathrm{e}-5$ \\
\hline & & & & & & & & & & & & 8,87 & 0,248 & $6,37 e-5$ \\
\hline & & & & & & & & & & & & 7,73 & 0,458 & $5,76 e-5$ \\
\hline
\end{tabular}

Table 3: Equivalent Von Mises stress and strain for contour nodes calculated by FE analyses for each growing step of the aneurysm. 


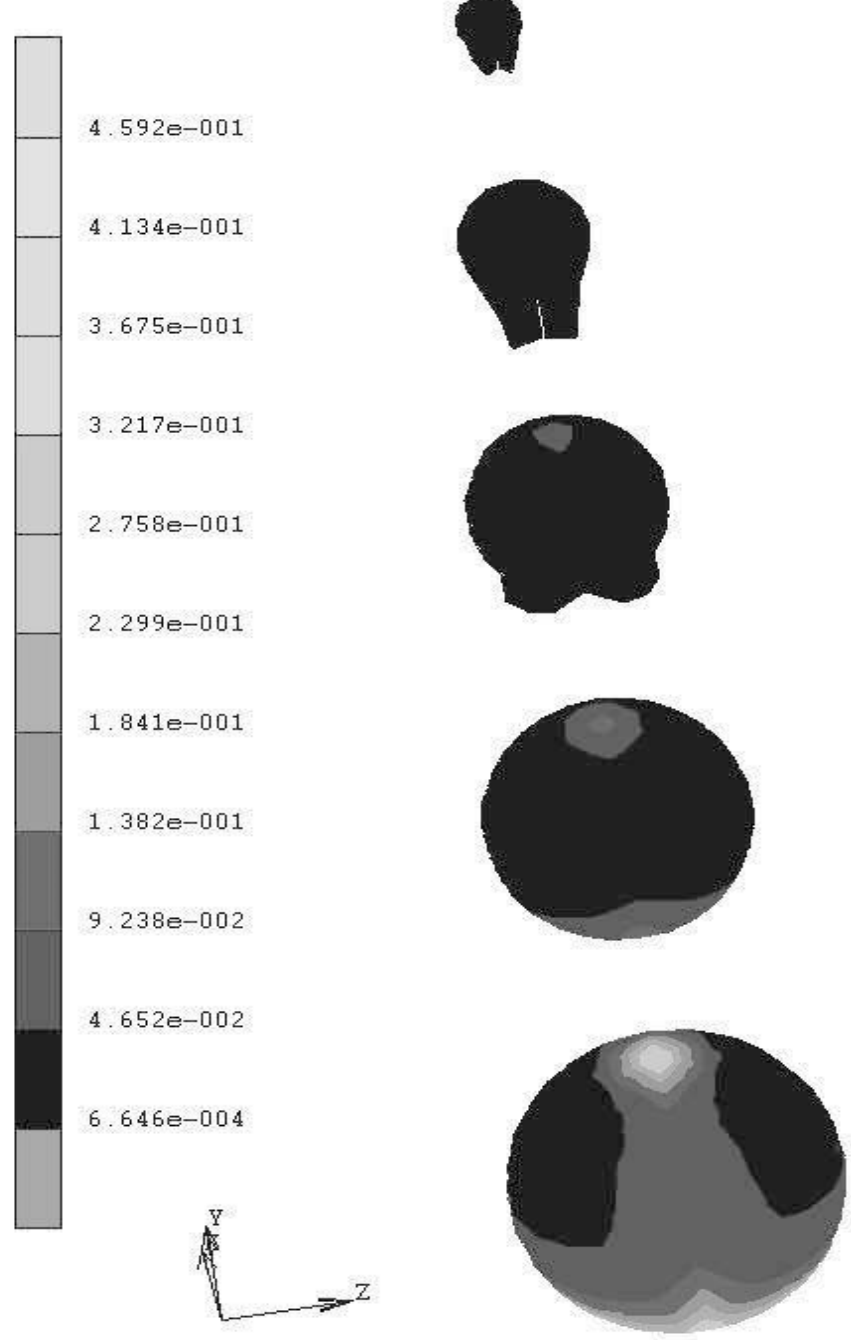

Figure 3: Contours maps of equivalent Von Mises stresses calculated for each growing step of aneurysm. term survival rates who can be safely managed conservatively. Less than $20 \%$ of the patients will need a surgical repair of their AAA in the first 5 years of follow-up. The finding that larger AAA within this group $(3.5-3.9 \mathrm{~cm})$ show a greater growth rate than smaller ones (from 3 to $3.4 \mathrm{~cm})(2.8$ vs. $1.65 \mathrm{~mm} /$ year $)$ has also been reported by other authors [48], (1.5-4.1 vs. $0.9-3.3 \mathrm{~mm} /$ year). Other authors have reported mean growth rates of 3-6.9 mm/year [49,50], for larger aneurysms from 4 to $5 \mathrm{~cm}$. The risk of rupture of these AAA has been estimated to be 0.6$2.1 \%$ per year [50]. Elger et al. [51], used a membrane shell model of an idealized axisymmetrical AAA to determine rupture as a function of wall curvature or bulge diameter. Increasing the pressure (100 to $160 \mathrm{mmHg}$ ) did not have a significant impact on peak wall stress. The values measured at a systolic pressure of $160 \mathrm{mmHg}$ did not increase any further than those at $140 \mathrm{mmHg}$. Finite Element Analysis has shown that the presence of atherosclerosis may elevate the wall stresses by $200 \%$ [52], probably through a mechanism of increased calcification and stiffness. Smaller AAAs, although structurally beginning to weaken, are strong enough to absorb circulatory pressures, it is only when a certain threshold of structural degeneration is reached that pressure begins to make significant contributions toward higher peak wall stress and greater risk of rupture. However, reduction of pressure does not stop the ongoing structural deterioration, which simply raises the peak stress curve for any given pressure, and significantly increases peak wall stress. Wall thickness and failure properties of an AAA represent the biomechanical manifestation of tissue degeneration and/ or regeneration. The implication of a given value of failure tension is best appreciated within the context of pressure-induced wall tension, Wang et al. [41], and Fillinger et al. [33] reported on finite element computation of pressure-induced wall stress in reconstructed models of human AAA, but assuming a uniform wall thickness. They reported wall 'tension' distribution scaled by a constant value, and the peak wall stress ranged from 22 to $78 \mathrm{~N} / \mathrm{cm}^{2}$ both reported by Fillinger for a wall thickness of $0.19 \mathrm{~cm}$ used for FEA. Raghavan et al. [32], noticed a dramatic reduction in wall thickness around the rupture site with readings of $0.23,0.62,0.78$ and $0.92 \mathrm{~mm}$ within an $8 \mathrm{~mm}$ radius. Even if the measurement at the exact ruptured site $(0.23 \mathrm{~mm})$ may be attributed to possible delaminations that may have occurred during rupture, the progressive reduction toward the rupture site suggests that this must have been a localized thin region prior to rupture. Di Martino et al. [21] reported on the failure properties of circumferentially oriented AAA

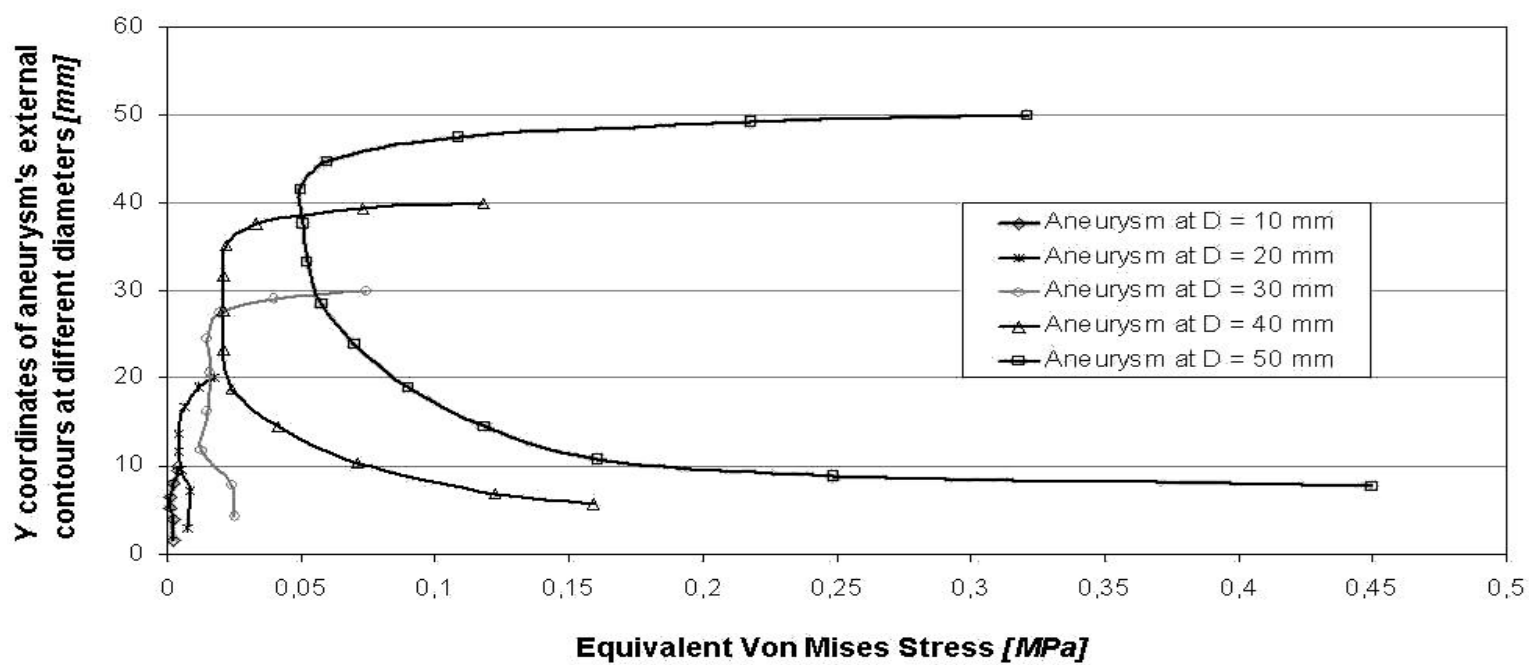

Figure 4: Curves of the $Y$ coordinate values in function of the corresponding Von Mises stresses. 
Citation: Bruschetta D, Mauro DD, Filardi V, Rizzo G, Trimarchi F (2015) On the Ratio between Static Pressure and Thickness of Growing AAAs. J Vasc Med Surg 3: 185. doi:10.4172/2329-6925.1000185

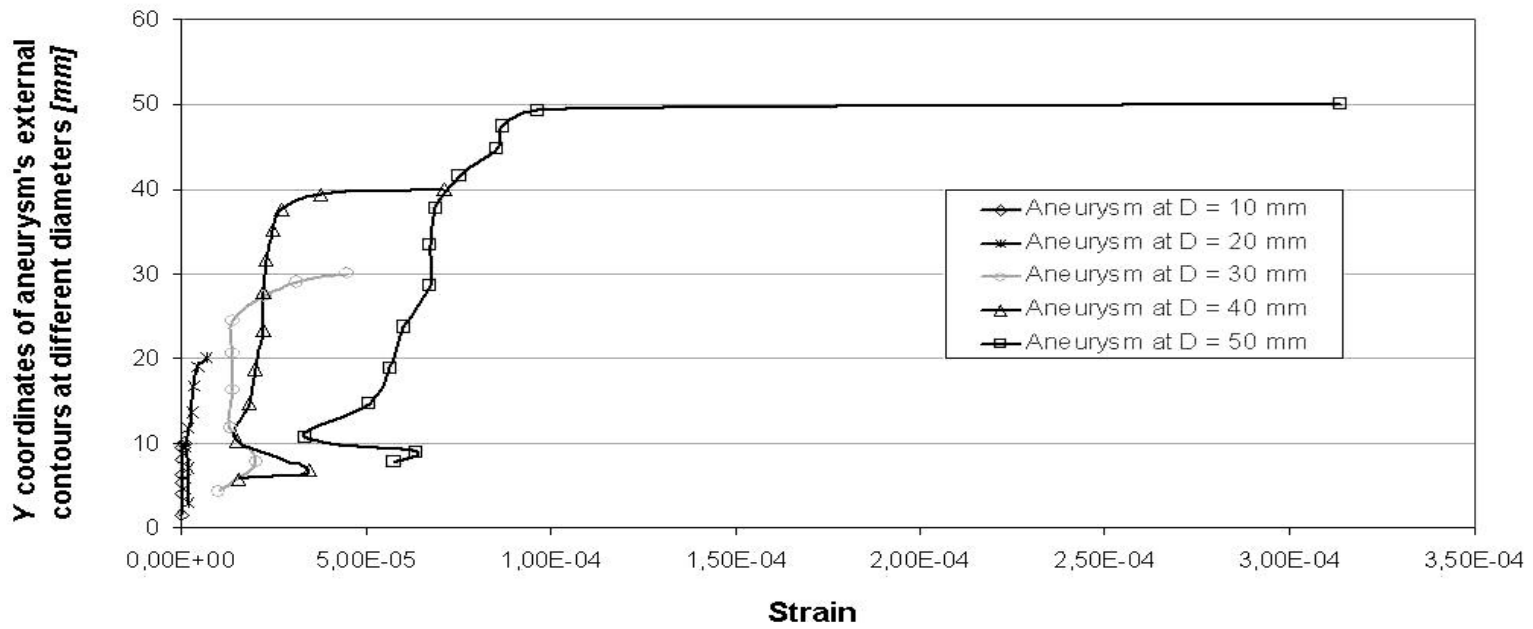

Figure 5: Curves of the $Y$ coordinate values in function of the corresponding Strains.

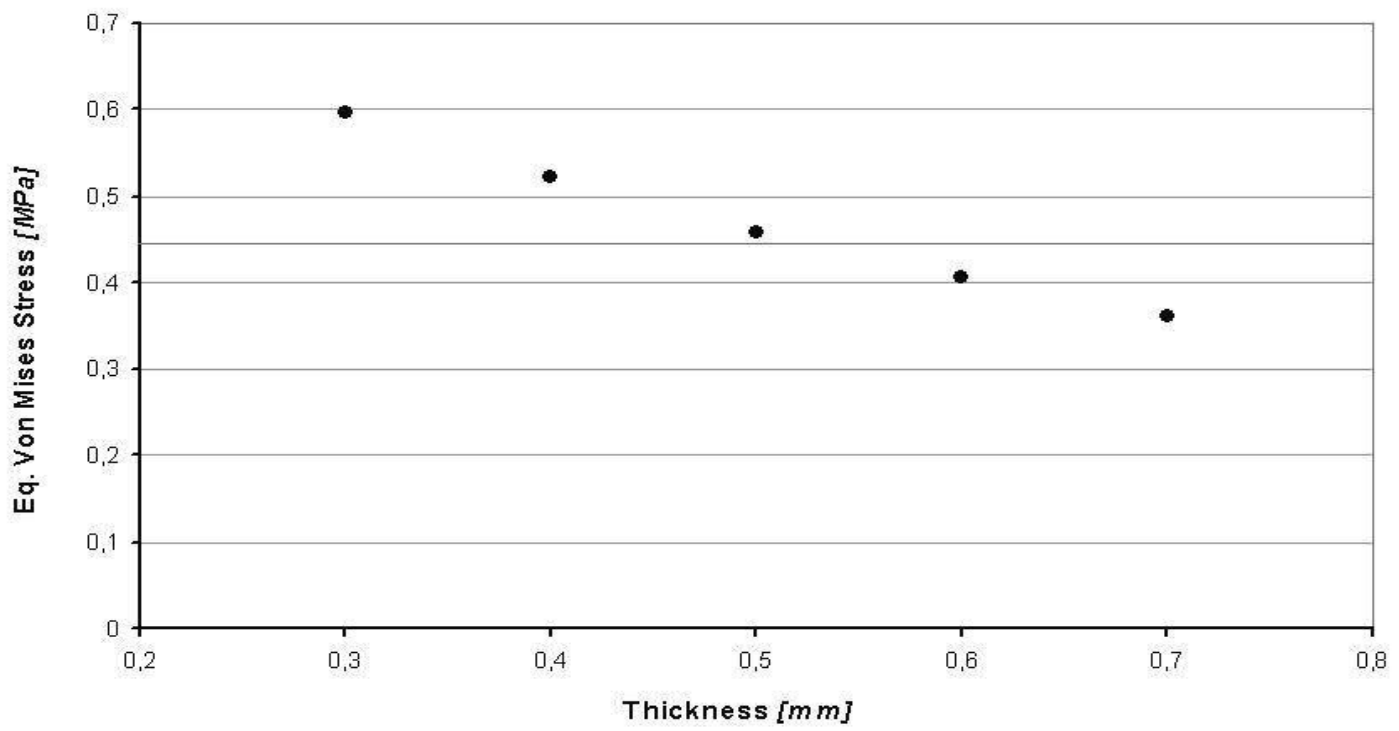

Figure 6: Equivalent Von Mises stress versus thickness (varying from 0,3 to $0,7 \mathrm{~mm}$ ) for aneurysm of $50 \mathrm{~mm}$.

tissue specimens harvested from anterior mid-section during surgical resection of 16 unruptured and 9 ruptured AAAs, obtaining a failure stresses of about $20-200 \mathrm{~N} / \mathrm{cm}^{2}$, evidencing that unruptured AAAs have a much wider range of failure stress values than ruptured AAAs. Nevertheless, Fillinger et al. [33] showed, by comparing simulations for lesions that ruptured versus those that did not (100 patients), that peak maximum normal stresses over 0,44 $\mathrm{MPa}$ correlate strongly with rupture potential. In closing, it is noted that many investigators [33,52] use the Von Mises stress to assess the "maximum stress" in AAAs. The Von Mises stress has utility in classical engineering analyses of ductile materials, which yield due to excessive shear stresses. In order to evaluate the mechanical behaviour of the cap, related to its thickness at $50 \mathrm{~mm}$ of diameter, different FEA were conducted varying thickness, uniformly, from 1 to $0.6 \mathrm{~mm}$. Results in terms of equivalent Von Mises stress and strain were reported in Table 2 and Figure 4 . As it is possible to notice, increment in stress is linked to a general reduction of the thickness. Thus by establishing a threshold value of $0,45 \mathrm{MPa}$, it can be argued that in an aneurysm's cap, subject to a inner static pressure of
19.000 MPa and of thickness $0,8 \mathrm{~mm}$, the equivalent Von Mises stress reaches $0,45 \mathrm{MPa}$, recognised as failure value.

\section{Conclusions}

In this paper was faced a new approach to investigate rupture phenomenon in AAA, by analysing the supposed thickness of the aneurysm's cap, its internal static pressure, and the equivalent Von Mises stresses induced on it. Results indicate that with an internal static pressure of $19.000 \mathrm{~Pa}$ and a thickness of $0.5 \mathrm{~mm}$, the equivalent Von Mises calculated is about $0,45 \mathrm{MPa}$, close the to failure value, and a critical dimension of $50 \mathrm{~mm}$. This means that failure conditions can depend at least by two variables: thickness and pressure. AAA can also crack at different values of pressure and thickness when critical values of these two parameters are reached. Another parameter which needs to be investigated is the velocity of growing in the aneurysm, and consequently the variations manifested on the mechanical properties of the involved tissues. Limitations to this study regard assumption 


\begin{tabular}{|c|c|c|}
\hline $\begin{array}{c}\text { Thickness } \\
{[\mathrm{mm}]}\end{array}$ & $\begin{array}{c}\text { Eq. Von Mises Stress } \\
{[\mathrm{MPa}]}\end{array}$ & $\begin{array}{c}\text { Strain } \\
\%\end{array}$ \\
\hline 0,7 & 0,361 & $2,60 \mathrm{E}-04$ \\
\hline 0,6 & 0,406 & $3,08 \mathrm{E}-04$ \\
\hline 0,5 & 0,459 & $3,70 \mathrm{E}-04$ \\
\hline 0,4 & 0,522 & $4,51 \mathrm{E}-04$ \\
\hline 0,3 & 0,596 & $5,62 \mathrm{E}-04$ \\
\hline
\end{tabular}

Table 4: Equivalent Von Mises stress and strain calculated by FE analyses for aneurysm of $50 \mathrm{~mm}$ varying thickness from 0,3 to $0,7 \mathrm{~mm}$.

that saccular aneurysms are perfectly spherical, thus predicted stress and strain fields are necessarily uniform, thus one cannot glean any insight on, for example, the propensity of rupture at the fundus, when the neck is thinner in an unloaded configuration. Future research will be focused in understanding links between internal static pressure and thickness at critical conditions, and how growing velocity can influence mechanical properties of tissues.

\section{Clinical Relevance}

The present research is the final part of an investigation focused on the evaluation of the static pressure aging inside the growing aneurysm in a first part and a second one, carried on in this paper, which has used precedent data to evaluate the critical stress aging on the cap of aneurysm by FEA, by varying the thickness of the cap. The aim is to identify a criterion which considers: the uncorrupted thickness of the blood vessel, evaluated closely to the disease, its decreasing law, the static pressure aging inside the cap, and finally the resultant stress aging on it.

\section{References}

1. Ouriel K, Green RM, Donayre C, Shortell CK, Elliott J, et al. (1992) An evaluation of new methods of expressing aortic aneurysm size: relationship to rupture. J Vasc Surg 15: 12-18.

2. Bengtsson H, Sonesson B, Bergqvist D (1996) Incidence and prevalence of abdominal aortic aneurysms, estimated by necropsy studies and population screening by ultrasound. Ann N Y Acad Sci 800: 1-24.

3. Patel MI, Hardman DT, Fisher CM, Appleberg M (1995) Current views on the pathogenesis of abdominal aortic aneurysms. J Am Coll Surg 181: 371-382.

4. Fleming C, Whitlock EP, Beil TL, Lederle FA (2005) Screening for abdominal aortic aneurysm: a best-evidence systematic review for the U.S. Preventive Services Task Force. Ann Intern Med 142: 203-211.

5. Boll AP, Severens JL, Verbeek AL, van der Vliet JA (2003) Mass screening on abdominal aortic aneurysm in men aged 60 to 65 years in The Netherlands. Impact on life expectancy and cost-effectiveness using a Markov model. Eur J Vasc Endovasc Surg 26: 74-80

6. Spurgeon D (2004) US screening programme shows high prevalence of aortic aneurysm. BMJ 328: 852

7. Brewster DC, Cronenwett JL, Hallett JW Jr, Johnston KW, Krupski WC, et al. (2003) Guidelines for the treatment of abdominal aortic aneurysms. Report of a subcommittee of the Joint Council of the American Association for Vascular Surgery and Society for Vascular Surgery. J Vasc Surg 37: 1106-1117.

8. Darling RC, Messina CR, Brewster DC, Ottinger LW (1977) Autopsy study of unoperated abdominal aortic aneurysms. The case for early resection. Circulation 56: Il161-164.

9. Nicholls SC, Gardner JB, Meissner MH, Johansen HK (1998) Rupture in smal abdominal aortic aneurysms. J Vasc Surg 28: 884-888.

10. Moore WS, Rutherford RB (1996) Transfemoral endovascular repair of abdominal aortic aneurysm: results of the North American EVT phase 1 trial. EVT Investigators. J Vasc Surg 23: 543-553.

11. Dryjski M, Driscoll JL, Blair RC, McGurrin MA, Dagher FJ, et al. (1994) The small abdominal aortic aneurysm: the eternal dilemma. J Cardiovasc Surg (Torino) 35: 95-100.

12. Geroulakos G, Nicolaides A (1992) Infrarenal abdominal aortic aneurysms less than five centimetres in diameter: the surgeon's dilemma. Eur J Vasc Surg 6 : 616-622.

13. Choksy SA, Wilmink AB, Quick CR (1999) Ruptured abdominal aortic aneurysm in the Huntingdon district: a 10-year experience. Ann R Coll Surg Engl 81: 2731.

14. Hall AJ, Busse EF, McCarville DJ, Burgess JJ (2000) Aortic wall tension as a predictive factor for abdominal aortic aneurysm rupture: improving the selection of patients for abdominal aortic aneurysm repair. Ann Vasc Surg 14: 152-157.

15. He CM, Roach MR (1994) The composition and mechanical properties of abdominal aortic aneurysms. J Vasc Surg 20: 6-13.

16. [UK Small Aneurysm Trial Participants] (1998) Mortality results for randomised controlled trial of early elective surgery or ultrasonographic surveillance for small abdominal aortic aneurysms. The UK Small Aneurysm Trial Participants. Lancet 352: 1649-1655.

17. May J, White GH, Waugh R, Chaufour X, Stephen MS, et al. (1999) Rupture of abdominal aortic aneurysms: A concurrent comparison of outcome of those occurring after endoluminal repair versus those occurring de novo. Eur J Vasc Endovasc Surg 18: 344-348.

18. Nyamekye IK (2001) Need for secondary interventions after endovascular repair of abdominal aortic aneurysms. Intermediate-term follow-up results of a European collaborative registry (EUROSTAR). Br J Surg 2000; 87: 1666-73.

19. Illig KA, Green RM, Ouriel K, Riggs P, Bartos S, et al. (1997) Fate of the proximal aortic cuff: implications for endovascular aneurysm repair. J Vasc Surg 26: 492-499.

20. Ashton HA, Buxton MJ, Day NE, Kim LG, Marteau TM, et al. (2002) The Multicentre Aneurysm Screening Study (MASS) into the effect of abdominal aortic aneurysm screening on mortality in men: a randomised controlled trial. Lancet 360: 1531-1539.

21. Di Martino E, Mantero S, Inzoli F, Melissano G, Astore D, et al. (1998) Biomechanics of abdominal aortic aneurysm in the presence of endoluminal thrombus: experimental characterisation and structural static computational analysis. Eur J Vasc Endovasc Surg 15: 290-299.

22. Di Martino ES, Bohra A, Vande Geest JP, Gupta N, Makaroun MS, et al. (2006) Biomechanical properties of ruptured versus electively repaired abdominal aortic aneurysm wall tissue. J Vasc Surg 43: 570-576.

23. Raghavan ML, Webster MW, Vorp DA (1996) Ex vivo biomechanical behavior of abdominal aortic aneurysm: assessment using a new mathematical model. Ann Biomed Eng 24: 573-582.

24. Vallabhaneni SR, Gilling-Smith GL, How TV, Carter SD, Brennan JA, et al. (2004) Heterogeneity of tensile strength and matrix metalloproteinase activity in the wall of abdominal aortic aneurysms. J Endovasc Ther 11: 494-502.

25. Sekhar LN, Heros RC (1981) Origin, growth, and rupture of saccular aneurysms a review. Neurosurgery 8: 248-260.

26. Humphrey JD (1995) Mechanics of the arterial wall: review and directions. Crit Rev Biomed Eng 23: 1-162.

27. Austin GM, Schievink W, Williams R (1989) Controlled pressure-volume factors in the enlargement of intracranial aneurysms. Neurosurgery 24: 722-730.

28. Akkas N (1990) Aneurysms as a biomechanical instability problem. In: Mosora, F. (Ed.), Biomechanical Transport Processes. Plenum Press, New York: 303311.

29. Canham PB, Ferguson GG (1985) A mathematical model for the mechanics of saccular aneurysms. Neurosurgery 17: 291-295.

30. Steiger HJ (1990) Pathophysiology of development and rupture of cerebral aneurysms. Acta Neurochir Suppl (Wien) 48: 1-57.

31. Sekhar LN, Sclabassi RJ, Sun M, Blue HB, Wasserman JF (1988) Intraaneurysmal pressure measurements in experimental saccular aneurysms in dogs. Stroke 19: 352-356.

32. Raghavan ML, Kratzberg J, Castro de Tolosa EM, Hanaoka MM, Walker $P$ et al. (2006) Regional distribution of wall thickness and failure properties of human abdominal aortic aneurysm. J Biomech 39: 3010-3016.

33. Fillinger MF, Marra SP, Raghavan ML, Kennedy FE (2003) Prediction of rupture risk in abdominal aortic aneurysm during observation: wall stress versus diameter. J Vasc Surg 37: 724-732.

34. Venkatasubramaniam AK1, Fagan MJ, Mehta T, Mylankal KJ, Ray B, et al 
Citation: Bruschetta D, Mauro DD, Filardi V, Rizzo G, Trimarchi F (2015) On the Ratio between Static Pressure and Thickness of Growing AAAs. J Vasc Med Surg 3: 185. doi:10.4172/2329-6925.1000185

Page 8 of 8

(2004) A comparative study of aortic wall stress using finite element analysis for ruptured and non-ruptured abdominal aortic aneurysms. Eur J Vasc Endovasc Surg 28: 168-176.

35. United Kingdom Small Aneurysm Trial Participants (2002) Long-term outcomes of immediate repair compared with surveillance of small abdominal aortic aneurysms. N Engl J Med 346: 1445-1452.

36. Vande Geest JP, Sacks MS, Vorp DA (2004) Age dependency of the biaxia biomechanical behavior of human abdominal aorta. J Biomech Eng 126: 815822.

37. Hatakeyama T, Shigematsu H, Muto T (2001) Risk factors for rupture of abdominal aortic aneurysm based on three-dimensional study. J Vasc Surg 33: $453-461$

38. Sonesson B, Sandgren T, Länne T (1999) Abdominal aortic aneurysm wall mechanics and their relation to risk of rupture. Eur J Vasc Endovasc Surg 18: 487-493.

39. Stenbaek J, Kalin B, Swedenborg J (2000) Growth of thrombus may be a better predictor of rupture than diameter in patients with abdominal aortic aneurysms. Eur J Vasc Endovasc Surg 20: 466-469.

40. Thubrikar MJ, Robicsek F, Labrosse M, Chervenkoff V, Fowler BL (2003) Effect of thrombus on abdominal aortic aneurysm wall dilation and stress. $J$ Cardiovasc Surg (Torino) 44: 67-77.

41. Vorp DA, Wang DH, Webster MW, Federspiel WJ (1998) Effect of intraluminal thrombus thickness and bulge diameter on the oxygen diffusion in abdominal aortic aneurysm. J Biomech Eng 120: 579-583.

42. Thubrikar MJ, al-Soudi J, Robicsek F (2001) Wall stress studies of abdomina aortic aneurysm in a clinical model. Ann Vasc Surg 15: 355-366.

43. Vande Geest JP, Di Martino ES, Bohra A, Makaroun MS, Vorp DA (2006) A biomechanics-based rupture potential index for abdominal aortic aneurysm risk assessment: demonstrative application. Ann N Y Acad Sci 1085: 11-21.

44. Vande Geest JP, Dillavou ED, Di Martino ES, Oberdier M, Bohra A, et al. (2006) Gender-related differences in the tensile strength of abdominal aortic aneurysm. Ann N Y Acad Sci 1085: 400-402.

45. Brady AR, Thompson SG, Fowkes FG, Greenhalgh RM, Powell JT; UK Smal Aneurysm Trial Participants (2004) Abdominal aortic aneurysm expansion: risk factors and time intervals for surveillance. Circulation 110: 16-21.

46. Lindholt JS, Heegaard $\mathrm{NH}$, Vammen S, Fasting $\mathrm{H}$, Henneberg EW, et al. (2001) Smoking, but not lipids, lipoprotein(a) and antibodies against oxidised $\mathrm{LDL}$, is correlated to the expansion of abdominal aortic aneurysms. Eur J Vasc Endovasc Surg 21: 51-56.

47. Brown PM, Sobolev B, Zelt DT (2003) Selective management of abdomina aortic aneurysms smaller than $5.0 \mathrm{~cm}$ in a prospective sizing program with gender-specific analysis. J Vasc Surg 38: 762-765.

48. Santilli SM, Littooy FN, Cambria RA, Rapp JH, Tretinyak AS, et al. (2002) Expansion rates and outcomes for the $3.0-\mathrm{cm}$ to the $3.9-\mathrm{cm}$ infrarenal abdominal aortic aneurysm. J Vasc Surg 35: 666-671.

49. Kurvers H, Veith FJ, Lipsitz EC, Ohki T, Gargiulo NJ, et al. (2004) Discontinuous, staccato growth of abdominal aortic aneurysms. J Am Coll Surg 199: 709-715

50. Lederle FA, Wilson SE, Johnson GR, Reinke DB, Littooy FN, et al. (2002) Immediate repair compared with surveillance of small abdominal aortic aneurysms. N Engl J Med 346: 1437-1444.

51. Elger DF, Blackketter DM, Budwig RS, Johansen KH (1996) The influence of shape on the stresses in model abdominal aortic aneurysms. J Biomech Eng 118: 326-332.

52. Inzoli F, Boschetti F, Zappa M, Longo T, Fumero R (1993) Biomechanical factors in abdominal aortic aneurysm rupture. Eur J Vasc Surg 7: 667-674. 